\title{
Study on the Logistics and Manufacturing Industry Linkage
}

\author{
Syed Abdul Rehman Khan ${ }^{1,2, *}$, Dong Qianli ${ }^{1}$, Zhang Yu ${ }^{3}$ \\ ${ }^{1}$ School of Economics and Management, Chang'an University, Xi'an, China \\ ${ }^{2}$ School of Supply Chain Management, Brasi-Business Research and Service Institute, Stroudsburg, PA, USA \\ ${ }^{3}$ School of Printing and Packaging, Xi'an University of Technology, Xi'an, China
}

Email address:

Sarehman_cscp@yahoo.com (S. A. R. Khan)

${ }^{*}$ Corresponding author

\section{To cite this article:}

Syed Abdul Rehman Khan, Dong Qianli, Zhang Yu. Study on the Logistics and Manufacturing Industry Linkage. Science Journal of Business and Management. Vol. 4, No. 4, 2016, pp. 137-143. doi: 10.11648/j.sjbm.20160404.16

Received: July 13, 2016; Accepted: August 11, 2016; Published: August 15, 2016

\begin{abstract}
The provincial two-industry linkage development mode is constructed, based on the theory of integration field, proposing the evaluation model about developing level which includes three dimensions: relationship, integration and process. With the FUZZY-membership-evaluation method, the comprehensive evaluation index is developed, that is the composite index of provincial two-industry linkage development, the way to improve the mode is also put forward from the integration field perspective.
\end{abstract}

Keywords: Logistics Industry, Integration Field, Joint-Key, Two-Industry Linkage Development Model, the Developing Level

\section{Introduction}

The facilitation of the joint development of the manufacturing industry and logistical industry has been conducted for more than three years. It plays an important role in improving manufacturing enterprises' core competitiveness and logistical enterprises' ability of integration services as well as the transformation of economic development. The joint development of the two industries in the province, how to choose indicators, and how to evaluate are basic and important themes for further studies. Making use of logistics integration field theory to grasp the main contradictions in the joint development of the two industries is an important approach for exploring into the problems, such as integrated entities and linkage keys, and conducting theoretical studies and practices of the joint development. Moreover, it is also a key method and approach to delve into the development level.

\section{Scope of Joint Development of the Two Industries with Integrated Field Theory}

\subsection{Integrated Field and Logistical Integration Field}

Logistical integration is an important field with relatively mature integrated field theory and practical application that plays an important role in the top design of logistics and supply chain. Moreover, integrated field is a more universal scope of basic theories. Various integrated entities and integrated field units are allocated and more under the effect of integrated force and integrated gravity. The manifestation forms in the studies with logistical integration process as the basic target are quite vivid. People tend to be more willing to accept it. Therefore, it is called logistical integrated field that refers to the state of allocation and movement of logistical integrated entities and various integrated field units under logistical integrated force and logistical integrated gravity. Logistical integrated field is not a natural one, but an artificial one. It is characterized with natural and economic attributes. Since the proposal of logistical integrated field [1], it has been applied in the studies on land bridge logistics in new Asian-Euro [2], international land port logistic [3, 4, 5, 6] and so on. The basic scope of logistical integrated field can better help us understand and know the key problems and main contradictions in the top design of logistics and supply chain management from the perspective of integrated field so that we can more profoundly know the basic theories, modes, mechanisms and systems of the joint development of manufacturing and logistical industry, design and realize the joint development of the two industries with higher efficiency. 


\subsection{Basic Scope of Logistical Integrated Field of the Joint Development of the Two Industries}

(1) Integrated entity. There are many types of integrated entities. In the joint development of the two industries, it mainly refers to manufacturing integrated entity and logistical integrated entity. The specific demonstrations are manufacturing and logistical enterprises $[7,8]$.

(2) Linkage key. The important role played by a field unit that is integrated by multiple field units. The comprehensive linkage keys focusing on information include VMI (Vendor Managed Inventory), JMI (Joint Managed Inventory) and collaborated predictions, CPFR (Collaborative Planning Forecasting And Replenishment) and regional logistical delivery \& regional distribution center dominated by the third logistical integrated entity. They all play the role of connections and unified operation $[9,10,11,12,13,14]$.

(3) Field line. Form and performances of connection between manufacturing supply chain and logistical service chain. Land bridge international logistics in new Asian-Euro demonstrates the logistical integrated operation process of "enterprise - land port - sea port overseas port - overseas land port - user". The joint integrated entities in the two industries can be connected by market selection mode, partnership mode, strategic union mode and relational integration mode. The performance of field line connection is reflected by efficiency, quality, cost and other indicators.

(4) Field boundary. The research target is the boundary of the operation process. According to the research objects, the studies can choose provincial area, economic region, country or world as the boundary.

\section{Analysis of Elements in the Joint Development of the Two Industries}

\subsection{Analysis of Elements in the Development of Integrated Entities}

Integrated entities are field units that are composed of subjective and passive field elements. They are special integrated field units that play an indispensable role in the joint development of the two industries. However, compared with manufacturing enterprises, general provincial logistical enterprises have the following problems:

(1) Logistical enterprises are in a disadvantageous position in the joint development of the two industries and relatively weak in dominating the linkage of the two industries. Take Shaanxi Province (China) as example. By 2011, the number of large-scale enterprises had reached 3,684, of which there had been 85 telecommunication equipment, computer and other electronic equipment manufacturing enterprises, 1,043 energy chemical enterprises, 731 equipment manufacturing industries, 162 medical manufacturing enterprises, 570 food enterprises, 138 textile clothing enterprises, 381 non-metal mineral product enterprises, and non-ferrous metallurgical enterprises. In addition, there had been 131,105 road cargo transportation companies and 123,448 individually-owned enterprises. In particular, there had been 79,525 ordinary cargo transportation companies, 72,058 individually-owned companies, 68 specific cargo transportation companies and 27 individually-owned companies, 39 large article transportation companies, 9 individually-owned companies, 307 dangerous cargo transportation companies.

(2) From the composition of integrated entities, in the comparison between subjective units (e.g.: practitioners' overall academic structure) and objective units (e.g.: quantity and quality of disposable resources), logistical enterprises are also weaker than manufacturing enterprises. Logistical enterprises are strategic entities, behavioral entities and profit-making entities composed of subjective and objective units. The subjective units are also weaker than those of manufacturing enterprises. Integrated entities' unit awareness is stressed, i.e., logistical enterprises should be the operating entities composed of dominant logistical chain. The strategic planning, plan design and resource integration should be stressed. In terms of objective units, except a minority of enterprises' specific resource units, logistical enterprises' universal resources and economic development strength are also weaker than those in manufacturing enterprises.

\subsection{Development of Linkage Key}

Linkage key refers to the effect relationship between field units, field units and seed nuclei in the logistical integrated field. The so-called "key" refers to one unit that forms or combines a closer interactive relationship through seed nuclei, field unit and field line. Usually, linkage key is used to abstractly reflect one overall unit of the connection between key factors in the logistical integration process. The linkage key of joint development of the two industries often adopts the following linkage methods.

(1) Functional linkage key. It is the linkage method between transportation and material inventory, product inventory and transportation functions. For example, 2.5 industries' linkage methods demonstrate the functional linkage key between different industries. The linkage is characterized with certain processing and technological depth. The close or relatively close relationship among different integrated entities is formed.

(2) Information-type linkage key. It includes singular information linkage, compound information linkage and comprehensive information system linkage. Contracts and so on are typical information-type linkage key. VMI and other methods are linkage keys that adopt information system to support logistical functions and technology. 
(3) Technological linkage key. The uniform and standard technological linkage is the basis of the construction of technological linkage key. For example, freezing inventory and freezing transportation as well as other cooling, measurement, control and management technology compose the linkage key.

(4) Resource-type linkage key. The linkage keys whose vehicles, warehouse, loading \& unloading equipment, transportation tools are different, but that are composed of compatible resources.

(5) Procedural linkage key. Logistical chain dominated by logistical integrated entities and supply chain dominated by manufacturing integrated entities compose linkage keys at the matching point. They often refer to effective linkage of two systems.

(6) Comprehensive linkage keys often choose one of the above linkage methods as the main one, supplemented with other linkage methods. Or they are composed of two of the above linkage methods.

\subsection{Operation Efficiency of Field Line}

Field line is the relationship of multiple field units. Using field link to express the logistical integration relationship is not only connotative, but also figurative and vivid. Field line is a vector. When its direction is consistent with the operation direction of the whole logistical integration system, it is called forward direction, otherwise it is called negative direction. Field line can be in the same field or cross fields. In the logistical integration system, field line is formed of logistical integrated entities and other various field units under the effect of logistical integrated force.

In the joint development of the two industries, manufacturing integrated entities and logistical integrated entities can realize the demands as well as internal pattern and requirements of logistical integration, choose corresponding unit organizations and form logistical resources, logistical functions, logistical integration procedure, operate the system and demonstrate the relationship of field line according to the goal and tasks of joint system of the two industries. The resources that compose the field line may be cross-entities, cross-regions and cross-boundary. However, the relationship between specific technology, organizations and business operation is quite close.

\section{Indicators that Measure the Joint Development of the Two Industries}

\subsection{Analysis of the Development of Basic Joint Mode of the Two Industries}

The two industries' joint mode is the basic pattern adopted by manufacturing and logistical enterprises for the purpose of maximizing the overall value of the supply chain so that the business procedure that it dominates realizes collaborative operation and development on the basis of their specialized operation. The closeness of linkage (cooperation) between logistical enterprises and manufacturing enterprises is demonstrated through relational dimension, integration dimension and procedural dimension. Moreover, the forms of the linkage of the two industries both at home and abroad are diverse. Therefore, the joint modes can be summarized as close-relationship type, logistics function type and logistical service procedure according to the closeness of the relationship between manufacturing and logistical enterprises, degree of integration of logistical services provided by logistical enterprises and the stage of the operation procedure of logistical business.

(1) The close relationship of the joint development of the two industries. The mode is the classification according to the joint relationship of the two industries. The matching degree of the linkage and operation between supply chain and logistical chain reflects the quality, efficiency and cost of the linkage between manufacturing industry and logistical industry. According to the competition and cooperation between manufacturing and logistical enterprise as well as the degree of closeness and harmony formed by the linkage, the modes can be classified into close integration type, strategic union type, partnership type and market selection type. Every mode can form one or multiple specific joint forms. Refer to Table 1 for details.

Table 1. Features and Type of Close-relationship.

\begin{tabular}{|c|c|c|}
\hline Type of close relationship & Basic features & Complex cases \\
\hline Close integration type & $\begin{array}{l}\text { Long-term cooperation history; crossing of business procedure; interactive } \\
\text { integration of resources; formation of logistical procedure of supply chain }\end{array}$ & $\begin{array}{l}\text { Shaanxi Tonghui, Xifei-Avic International, } \\
\text { etc. }\end{array}$ \\
\hline Strategic union type & $\begin{array}{l}\text { Long-term cooperation contract with more than one year: clear business } \\
\text { boundary }\end{array}$ & $\begin{array}{l}\text { Baoji Petroleum-Weixin, Media-Annto } \\
\text { Logistics, SAIC-Anji Logistics }\end{array}$ \\
\hline Partnership type & $\begin{array}{l}\text { Medium and short-term cooperation contract within one year: clear business } \\
\text { contents and boundary }\end{array}$ & $\begin{array}{l}\text { BYD-Huaqin Logistics, Xihe-Shaanxi } \\
\text { Logistics, Xihe-Zebra Logistics, etc. }\end{array}$ \\
\hline Market selection type & Temporary market selection; clear boundary & $\begin{array}{l}\text { Automobile Cargo Station, Logistics Park, } \\
\text { etc. }\end{array}$ \\
\hline
\end{tabular}

(2) Two industries' joint logistical function mode. The classification is the joint mode of the two industries pertinent to logistical service suppliers. According to the integration of logistical functions provided by logistical suppliers for manufacturing enterprises, they can be classified into logistical service suppliers, functional logistical service suppliers and logistical resource service suppliers. Integrated logistical service suppliers can provide all or all-procedural logistical services in one field for manufacturing enterprises. 
Functional logistical service suppliers merely provide several logistical services but not all or all-procedural logistical services for manufacturing enterprises, including transportation or inventory. In addition, logistical resource suppliers mainly provide inventory, vehicles, cranes, forklifts and other logistical resources, but do not provide integrated or functional logistical services directly for manufacturing enterprises. Refer to Table 2 for details.

Table 2. Main Features of Logistical Functional-Mode.

\begin{tabular}{|c|c|c|}
\hline Type of basic services & Main features & Typical cases \\
\hline Integrated logistical service supplier & Provide overall and all-procedural logistical services & Shaanxi Tonghui, \\
\hline Logistical functional service supplier & Provide transportation or inventory and several logistical services & Huain Logistics - BYD [Note] \\
\hline Logistical resource service supplier & Provide inventory, vehicles, cranes, forklifts and other logistical resources & Huayu Logistics - social logistics \\
\hline
\end{tabular}

Note: BYD’s logistics partners include Huaqin Logistics, Anji Transportation, Zhonglian Logistics, Wuhan Xingda, Changchun Hongda, Shenyang Yuandong, Chongqing Yuanzhida, etc. Huaqin Logistics occupies 50\% of BYD's completed vehicle transportation. It is the largest partner.

In the logistical functional mode, the logistical enterprises' integration development direction is: from logistical resource service supplier to logistical functional service supplier and then to integrated logistical service supplier.

(1) Two industries' joint service procedure mode. It is the classification of the depth of two industries' joint services provided for logistical enterprises. According to logistical business, it can be classified into three joint forms, i.e., operation of logistical business, all-procedural monitoring and plan design. The latter is often on the basis of the former one. Moreover, it cannot be separated from the former one. (Refer to Table 3).

Table 3. Features and Typical/Complex Cases of Logistical Service Procedure Mode.

\begin{tabular}{lll}
\hline Depth of logistical service procedure & Main features & Typical cases \\
\hline Plan design & Separate of make use of think tank in plan design & $\begin{array}{l}\text { Shaanxi Automobile-Tonghui Logistics, Antaida } \\
\text { Logistics -Little Swan, TNT Logistics - HP } \\
\text { All-procedural monitoring management }\end{array}$ \\
$\begin{array}{ll}\text { Execute monitoring management's functions } \\
\text { Logistical business operation }\end{array}$ & $\begin{array}{l}\text { Shaanxi Automobile - Tonghui Logistics, Antaida } \\
\text { Logistics - Little swan, TNT Logistics - HP }\end{array}$ \\
\hline
\end{tabular}

\subsection{Indicators That Evaluate the Joint Development of the Two Industries and Model Estimation}

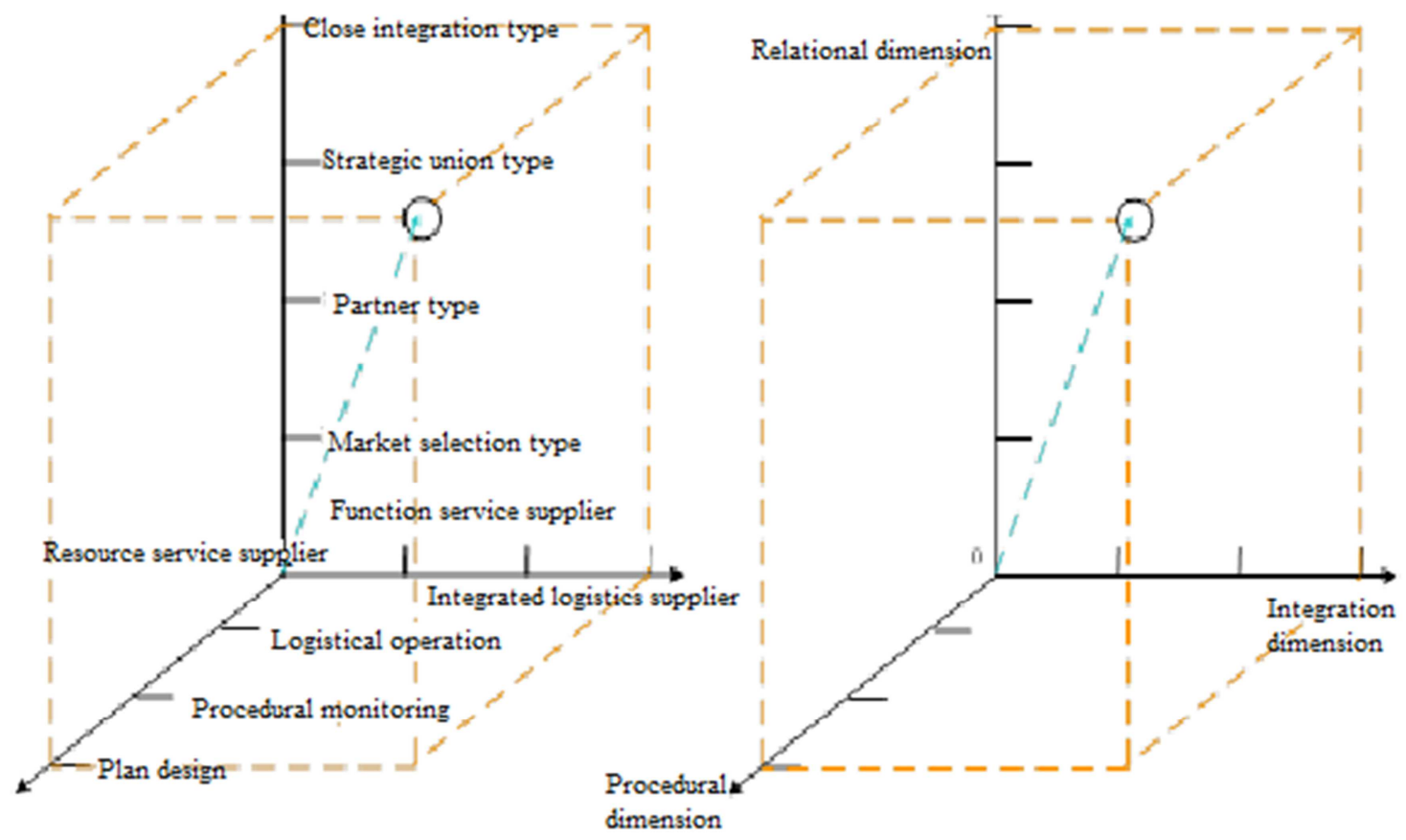

Figure 1. Evaluation on Two Industries'Joint Mode and Spatial Structure.

From the statistical perspective, the closer the logistical chain and supply chain in logistical enterprises and manufacturing enterprises are related, the more efficient the joint development is. Therefore, in the dynamic cooperation of the connection and integration of different industries, the closer the connection is, the higher the service quality and efficiency of logistics is. According to the three basic modes in Table 1, 2 and 3 , the main 
indicators are as follows:

(1) The indicators of the relational closeness (\%) are respectively the degree of closeness of "market selection", "partner", "strategic union" and "close integration" in the cooperation of two enterprises.

(2) Business integration degree (\%) indicators are respectively the popularity degree of "logistical resource services", "logistical functional services" and "integrated logistical services" in logistical enterprises.

(3) Depth of logistical services (\%) are respectively the degree of business popularity of "logistics business operation", "all-procedural monitoring management" and "plan design". The two industries' joint mode evaluation system evaluates the closeness degree of connection (cooperation) between logistical and manufacturing enterprises under the condition of manufacturing enterprises' logistical business outsourcing. The evaluation can be divided into three dimensions, i.e., relational dimension, integration dimension and procedural dimension. The integration and procedural dimensions are mainly demonstrated as the internal cause effect in logistical enterprises. Relational dimension involves the relationship between manufacturing and logistical enterprises. (Refer to Fig: 1).

According to FUZZY membership theory and Fuzzy mathematical comprehensive evaluation method, the two industries' joint development evaluation mode is set up. The development measured by integration dimension $\mu(x)$, procedural dimension $\mu(y)$ and relational dimension $\mu(z)$ can be expressed by Formula 1, 2 and 3 respectively with each component in vector $\bar{\mu}$ model. The corresponding weight is $\bar{W}$. The two industries' development measurement model is Formula 4, i.e.,

$$
\begin{aligned}
& \mu(x)=e^{-12.77(x-0.5)^{2}} \\
& \mu(y)=e^{-12.77(y-0.5)^{2}} \\
& \mu(z)=e^{-19.95(z-0.4)^{2}}
\end{aligned}
$$

The two industries' joint level is calculated with Formula 4.

$$
L=\left[\begin{array}{lll}
W_{(\mathrm{x})} & W_{(\mathrm{y})} & W_{(\mathrm{z})}
\end{array}\right]\left[\begin{array}{lll}
\mu_{(\mathrm{x})} & \mu_{(\mathrm{y})} & \mu_{(\mathrm{z})}
\end{array}\right]^{T}
$$

Take the sample of the actual investigation in (SXFGW-02) topic in basic calculation. At present, in the two industries' joint development modes, market selection, partner type, strategic union type and close integration type occupy $27.6 \%$, $37.9 \%, 27.6 \%$ and $6.9 \%$ respectively. The corresponding accumulative weight in relationship is respectively $0.25,0.50$, 0.75 and 1. After uniformization, the membership weight of the relational dimension can be obtained. Combining with market investigation, the weight is shifted to membership according to the percentage. The membership degree of the relational dimension of the two industries in Shaanxi Province can be obtained:

$$
[0.10,0.20,0.30,0.40][27.6 \%, 37.9 \%, 27.6 \%, 6.9 \%]^{\mathrm{T}}=0.2138
$$

Take it to Formula 3, the horizontal membership degree of the relational dimension is: $\mu(\mathrm{z})=e^{-19.95(0.2138-0.40)^{2}}=0.5007$

In the logistical integration mode, logistical resource service, functional logistical service and integrated logistical services occupy $10.3 \%, 82.8 \%$ and $6.9 \%$ respectively. The accumulative weight at the integration dimension is respectively $0.33,0.67$ and 1 . After uniformization, the weight of membership degree can be obtained. Combining with market investigation, the weight is shifted to membership according to the percentage. The membership degree of the integration dimension of the two industries in Shaanxi Province can be obtained:

$$
[0.167,0.333,0.500][10.3 \%, 82.8 \%, 6.9 \%]^{\mathrm{T}}=0.3274
$$

In the logistical procedural mode, logistical business operation, all-procedural monitoring management and plan design occupy $79.4 \%, 10.3 \%$ and $10.3 \%$ respectively. The corresponding weight at the procedural dimension is respectively $0.33,0.67$ and 1 . After uniformization, the membership weight of the procedural dimension can be obtained. Combining with market investigation, the weight is shifted to membership according to the percentage. The membership degree of the procedural dimension of the two industries in Shaanxi Province can be obtained:

$$
[0.167,0.333,0.500][79.4 \%, 10.3 \%, 10.3 \%]^{\mathrm{T}}=0.2184
$$

The horizontal membership degree of the integration dimension, procedural dimension and relational dimension of vector $\bar{\mu}$ component of the two industries' joint development in Shaanxi Province is respectively:

The level at the integration dimension is: $\mu(x)=e^{-12.77(0.3274-0.5)^{2}}=0.6836$

The level at the procedural dimension is: $\mu(\mathrm{y})=e^{-12.77(0.2184-0.5)^{2}}=0.3632$

The level at the relational dimension is: $\mu(\mathrm{z})=e^{-19.95(0.2138-0.4)^{2}}=0.5007$

Pertinent to three-dimensional evaluation indicators of the two industries' joint development, the following judgment matrix is obtained. Refer to Table 4.

Table 4. Judgment Matrix for the Three-dimensional Evaluation Indicators of the Two Industries'Joint Development.

\begin{tabular}{llll}
\hline $\mathbf{O}$ & Relational dimension $(\mathrm{Z})$ & Procedural dimension $(\mathbf{Y})$ & Integration dimension $(\mathbf{X})$ \\
\hline Relational dimension $(\mathrm{Z})$ & 1 & $5 / 7$ & $5 / 8$ \\
Procedural dimension (Y) & $7 / 5$ & 1 & $5 / 7$ \\
Integration dimension (X) & $8 / 5$ & $7 / 5$ & 1 \\
\hline
\end{tabular}


In the establishment of judgment matrix, the consistency before and after judgment should be ensured. After calculation, $\mathrm{CR}=0.0667$. Each dimension's weight [0.426, 0.325, 0.249]. In particular, $\mathrm{CR} \leqq 0.1$, which indicates that judgment matrix is satisfactorily consistent. The weight can be adopted. Therefore, by using the two industries' joint development's comprehensive index Formula 4, the development level index is 0.5339 , i.e.:

$$
\begin{aligned}
& L=\left[\begin{array}{lll}
W_{(\mathrm{x})} & W_{(\mathrm{y})} & W_{(\mathrm{z})}
\end{array}\right]\left[\begin{array}{lll}
\mu_{(\mathrm{x})} & \mu_{(\mathrm{y})} & \mu_{(\mathrm{z})}
\end{array}\right]^{T} \\
& =[0.426,0.325,0.249][0.6836,0.3632,0.5007]^{T}=0.5339
\end{aligned}
$$

According to Table 5, it can be seen that the joint development in the province is still at Level-4, i.e., just so-so. The development space is quite large.

Table 5. Meaning of values of membership degree of two industries'joint integration.

\begin{tabular}{llllll}
\hline Evaluation scale & Leading (Level 1) & Outstanding (Level 2) & Satisfactory (Level 3) & Just so-so (Level 4) & Weak (Level 5) \\
\hline Membership degree U & $\geq 0.97$ & $\geq 0.89$ & $\geq 0.78$ & $\geq 0.50$ & $<0.50$ \\
\hline
\end{tabular}

The improvement of joint development of the two industries in Shaanxi Province lies in procedural dimension. The subjective units in the integrated entities still need further perfection in terms of logistical all-procedural monitoring management and plan design. In this way, the manufacturing integrated entities' adoption of strategic union can provide convenience for giving play to the integrated force of integrated entities, providing integrated logistical service plan and forming sound harmonious relationship among integrated entities. In this way, the membership degree of other two dimensions also increases.

\section{Conclusion}

From the above study, the following conclusions can be concluded:

(1) The two industries' joint development level model is simple, accurate and feasible. The indicator system is universal and conducts absolute evaluation. Besides, the horizontal comparison evaluation can be carried out. As long as the percentage of sampling investigation with model classification is available, the model can be used in measurement. The investigation data in relevant provinces can be used in the horizontal comparison among different provinces.

(2) Integration dimension and procedural dimension more demonstrate the internal cause requirements on the growth of logistical integrated entities, especially logistical integrated service ability, all-procedural monitoring and plan design ability. If necessary, think tank should be used to improve logistical integrated entities' decision-making ability. Relational dimension involves more external causes, showing the relationship between logistical integrated entities and manufacturing integrated entities.

(3) The two industries' development space can be sought in the plan design of integrated entities and linkage key. In the two industries' joint system and procedural design, the design, application and efficiency of linkage key among integrated entities play the supportive role in the field line's quality, efficiency and cost. Integrated logistical service suppliers need the ability of plan design of linkage key and realizing operation.
(4) In the competition and cooperation among different integrated entities, the specialized logistical enterprises with certain specific resources can form relatively stable partnership or strategic union relationship with manufacturing enterprises. The relationship between the two joint enterprises develops toward close integration type from a disperse type. The design and application of linkage key is of great importance. Logistical integration field theory lays a sound foundation for it.

(5) Enhancing the awareness of integrated entities and fostering integrated power is a long-term task. The weak awareness of logistical integrated entities, unfamiliarity with the differential services in different manufacturing enterprises or how to provide appropriate services are the reasons why the enterprises are at a disadvantageous position in the two industries' joint development. Enterprises should cultivate the awareness of integrated entities, form integrated force from the design and establishment of linkage key, and realize the final goal and values in the establishment and integrated operation of proper or multiple linkage keys.

\section{References}

[1] Dong Qianli, Yan Fei. Logistics Introduction Theory \& Implementation Mechanism [M], Social Sciences Academic Press, 2011, 32.

[2] Dong Qianli. the existing problems of new Euro-Asia continental bridge integration [J]. NEW SILK R OAD HORIZON, 2012 (09): 42-44.

[3] Dong Qianli, Dong Zhan, Strategic consideration of extending hinterland of ports in logistics integration field perspective [J]. China Ports, 2012 (02): 56-58, 63.

[4] Dong Zhan, Dong Qianli, Main ideas and basic categories in establishing integrated logistics field [J], Logistics technology. 2012 (05): 1-3, 10.

[5] Dong Qianli, Logistics Integration Field: Theory \& Practice of International Land Port [M], Social Sciences Academic Press, 2012: 15-18.

[6] Li Yibin, Dong Qianli, Analysis of logistics outsourcing contract with the consideration of business scale and economic environment [J], Statistics and Decisions, 2012 (09): 56-58. 
[7] Guru, M. V., \& Horne, J. E. (1999). Labeling of GMO's: Impact on Consumer Demand and Global Food Trade. Nature Biotechnology, 17, 43-43.

[8] Khan, S. A. R, and Dong, Q., (2015a) Case of civic company: The implementation of enterprise resource planning, International business research, vol. 8, no. 11, November 2015.

[9] Khan, S. A. R, and Dong, Q., Zhang, Y. (2015a) Classification of important and critical factors in enterprise resource planning, Life science journal, Zhengzhou University, vol. 12, December 2015.

[10] Khan, S. A. R, and Dong, Q., (2015b) An analysis of information sharing in supply chain: Two friend countries, International journal of innovative research and development, vol. 4, issue. 11, 2015.
[11] Khan, S. A. R, and Dong, Q., Zhang, Y. (2015b) Analysis and Usage: Cloud computing technology in the supply chain management, Life science journal, Zhengzhou University, vol. 12, December 2015.

[12] Khan, S. A. R. (2015a) Role of global sourcing in the modern supply chain of "FMCG" industries, China marketing international conference 2015 Proceedings.

[13] Khan, S. A. R. (2015b) Challenges and Benefits: Global sourcing vs. local sourcing in the manufacturing industry, China marketing international conference 2015, Proceedings.

[14] Khan, S. A. R. (2015c) Barriers and Drivers: Information Technology in Manufacturing Firms of Australia, China marketing international conference 2015, Proceedings. 